\title{
PANORAMA MUNDIAL DO DESPERDÍCIO E PERDA DE ALIMENTOS NO CONTEXTO DE CADEIAS DE SUPRIMENTOS AGROALIMENTARES
}

Camila Colombo de Moraes* Thiago Alves de Souza**

RESUMO: O desperdício e a perda de alimentos vêm criando uma necessidade de investigação, principalmente no contexto de cadeias agroalimentares, assim, o objetivo desse artigo foi fornecer um panorama do desperdício e da perda de alimentos em cadeias de suprimentos agroalimentares, tais como a de carnes, frutas, legumes e verduras e de cereais e grãos em um contexto mundial, apontando como ocorre 0 desperdício e a perda em cada cadeia, além de seus principais impactos e desafios. Através de uma revisão da literatura em bases de dados e em órgãos representativos à pesquisa, foi possível observar que a cadeia que mais se destaca com relação ao desperdício e a perda é a de frutas, legumes e verduras, embora seu impacto ambiental não seja tão representativo como a de carnes, que utiliza um grande número de recursos em seus processos, o volume perdido é expressivo. Com relação aos elos da cadeia, os que sofrem mais impacto com relação à perda são os de produção, pós-colheita, processamento e transporte, sendo mais representativos em países em desenvolvimento. Já os países desenvolvidos, os elos que mais se destacam com relação ao desperdício são o de distribuição (varejo) e consumo. É de extrema importância que haja o estabelecimento de uma abordagem holística entre todos os elos da cadeia, através de estudos mais aprofundados será possível entender os problemas encontrados por cada elo da cadeia, bem como criar estratégias e recursos mais adequados para a realidade encontrada em cada país.

PALAVRAS-CHAVE: Cadeia de suprimento agroalimentar; Desperdício de alimentos; Perda de alimentos; Sustentabilidade.

\footnotetext{
* Doutoranda em Engenharia de Produção pela Universidade Federal de São Carlos (DEP/PPGEP/UFSCar), Brasil. E-mail: camila.cmoraes@hotmail.com

** Doutorando em Engenharia de Produção pela Universidade Federal de São Carlos (DEP/PPGEP/UFSCar), Brasil.
} 


\title{
WORLD SCENARIO ON FOOD WASTE AND LOSS WITHIN AGRO- FOOD SUPPLY CHAINS
}

\begin{abstract}
Waste and loss of food require an investigation mainly within the context of agro-food chains. Current study provides a scenario of food waste and loss in agro-food supply chains, such as meat, fruits, legumes, vegetables, cereals and grains worldwide. The study provides the manner waste and losses occur in each chain, impacts and challenges. A review of the literature from databases and representative research groups shows that the most important chain causing waste and loss is that comprising fruits, legumes and vegetables. However, its environmental impact is not as representative as that of meat with its great number of resources in its process. Volume is, however, significant. Production, post-harvest, processing and transport links, especially in developing countries, have the greatest impact with regard to loss. In developed countries, distribution and consumption are the most significant waste links. It is highly important that a holistic approach is established between all chain links through in-depth studies. The latter explains the issues involved in each chain link and establishes more adequate strategies and resources for each country.
\end{abstract}

KEY WORDS: Agro-food supplementation chain; Food wastes; Food losses; Sustainability.

\section{INTRODUÇÃO}

A população mundial de 7,2 bilhões tem previsão para um aumento de quase um bilhão de pessoas nos próximos 12 anos, atingindo 8,1 bilhões em 2025 e 9,6 bilhões em 2050. A maior parte do crescimento populacional ocorrerá em regiões em desenvolvimento, que são projetadas a aumentar de 5,9 bilhões em 2013 para 8,2 bilhões em 2050. No mesmo período, a população das regiões desenvolvidas permanecerá praticamente inalterada em torno de 1,3 bilhão de pessoas (UN, 2013).

Para suprir o aumento da população mundial, os países deverão investir na produção e distribuição de alimentos. Porém, o maior problema não está em propriamente aumentar a produção de alimentos, mas sim na sua distribuição, o que acarreta em maiores perdas no processo e contribui significativamente para problema da fome no mundo (FAO, 2013). Fatores como mudanças climáticas e recursos limitados - como o solo para plantio - podem interferir na produção de alimentos no futuro. 
A perda e/ou desperdício de alimentos é visto como uma importante questão de sustentabilidade por várias razões. Do ponto de vista ambiental, o desperdício contribui para as emissões de gases do efeito estufa durante a disposição final em aterros e durante atividades associadas à produção, processamento, fabricação, transporte, armazenamento e distribuição de alimentos (PAPARGYROPOULOU et al., 2014). O alimento que é produzido para consumo humano, mas que acaba não sendo consumido, é um desperdício de recursos naturais como terra, energia e água, e leva a interrupções de ciclos biogênicos devido principalmente às atividades agrícolas intensivas (GÖBEL et al., 2015). Com relação à perspectiva social são atribuídos à dimensão ética e moral dentro do conceito geral de segurança alimentar global. Aproximadamente um terço dos alimentos para consumo humano (1,3 bilhões de toneladas por ano) é perdido ou desperdiçado em todo o mundo (GUSTAVSSON et al., 2011). Já com relação aos impactos econômicos, estes são devido a custos relacionados ao desperdício de alimentos e seus efeitos sobre os agricultores e os rendimentos dos consumidores (PAPARGYROPOULOU et al., 2014), uma vez que o varejo repassa o valor das perdas no preço final dos produtos.

As perdas e desperdícios de alimentos ocorrem ao longo de toda a cadeia de suprimentos: $28 \%$ ocorrem no âmbito do consumidor; $28 \%$ na produção; $17 \%$ no mercado e distribuição; $22 \%$ durante o manuseio e armazenamento e os $6 \%$ restantes na etapa de processamento (PORTAL BRASIL, 2014). No caso do Brasil, quarto maior produtor mundial de alimentos, cerca de 140 mil toneladas de alimentos são produzidas por ano, porém, cerca de 40 mil toneladas de alimentos são desperdiçadas por dia, 26,3 milhões de toneladas por ano (FAO, 2013; EMBRAPA, 2015).

Nesse contexto, a cadeia de suprimentos agroalimentar merece destaque, visto que seu desperdício possui um grande impacto ambiental, social e econômico (DARKOW et al., 2015; FAO, 2016; GLOVER et al., 2014). Os desafios enfrentados por essa cadeia devem ser tratados com cautela, devido à complexidade das suas interações, dos seus processos de logística, fabricação e processamento, distribuição e consumo de alimentos, especialmente no que diz respeito à eficiência logística, qualidade, segurança e sustentabilidade (GÖBEL et al., 2015). Além disso, já é conhecido que essa cadeia possui algumas especificidades (BATALHA; SILVA, 2007) como a sazonalidade de disponibilidade de matéria-prima, variações de qualidade de matéria-prima, perecibilidade da matéria-prima e do produto final e sazonalidade de consumo. 
O desperdício e a perda de alimentos são importantes questões de sustentabilidade que vêm criando uma necessidade de investigação, principalmente no contexto de cadeias agroalimentares, devido às suas peculiaridades, além disso, é um problema enorme reconhecido em todo o mundo, apesar da definição de vários termos relacionados à temática e o processo de obter informações ainda não estar bem resolvido (GARRONE et al., 2014). Diante disso, o objetivo desse artigo é fornecer um panorama do desperdício e da perda de alimentos em cadeias de suprimentos agroalimentares em um contexto mundial, apontando como o desperdício e a perda são tratados em países com desenvolvimento distintos, como ocorre em cada cadeia, além de seus principais impactos e desafios.

\section{PROCEDIMENTOS METODOLÓGICOS}

O presente estudo é caracterizado como exploratório tendo como intenção fornecer os subsídios necessários para a compreensão das questões relativas em como ocorre o desperdício e a perda de alimentos em diferentes tipos de cadeia de suprimentos agroalimentares em nível mundial. Além disso, fundamenta-se nos pressupostos da pesquisa qualitativa, pois busca estudar um fenômeno contemporâneo em profundidade e em seu contexto de vida real, especialmente quando os limites entre o fenômeno e o contexto não são claramente evidentes (ELLRAM, 1996; JOHNSON et al., 2007). Esta abordagem de pesquisa permite aqui examinar conceitos em termos de significados e interpretação de um fenômeno em um contexto específico - cadeia agroalimentar.

Por meio da revisão de literatura, as análises aqui apresentadas estarão baseadas nas visões de diferentes autores, mas sem a presença de dados de campo. Para fundamentação deste método, a questão de pesquisa foi "Como ocorre o desperdício e a perda de alimentos em diferentes tipos de cadeia de suprimentos agroalimentares em nível mundial?". Através desse procedimento, foi possível realizar reflexões a partir de um fenômeno relatado pela literatura, ou seja, o desperdício e a perda de alimentos (BERTO; NAKANO, 1998).

A partir do questionamento da pesquisa, foi elaborada uma busca genérica adaptada para duas bases de dados (ISI Web of Science e Scopus), onde inseridas as 
palavras-chave ligadas ao tema foi possível obter informações que respondessem a referida questão de pesquisa. Segundo Giordano e Biolchini (2012) essas duas bases de dados oferecem rapidez e facilidade na obtenção de documentos, abrangência de conteúdos nas diversas áreas do conhecimento, e principalmente, demonstram o que há de mais recente nas pesquisas científicas em determinado tema. Além das bases de dados, foram consultadas teses, livros, e sites da Internet relevantes à temática de pesquisa, como FAO, ONU, UNEP, EMBRAPA, MAPA, MCTI, e outros, esse sites foram de extrema importância por fornecerem dados (principalmente quantitativos) e conceitos mais específicos ao assunto do que os artigos científicos. As palavras-chave utilizadas nas bases de dados foram: "food waste"; "food loss"; "supply chain*"; "agrifood*"; "agrifood supply chain*". O asterisco (*) foi utilizado como forma de captar todas as variações da palavra. Os documentos que não foram obtidos nas consultas nas bases de dados, mas através de pesquisas de forma aleatória na Internet, tiveram suas buscas adaptadas exatamente sobre o tópico necessário. A Figura 1 apresenta oframework de como foi realizada a pesquisa.

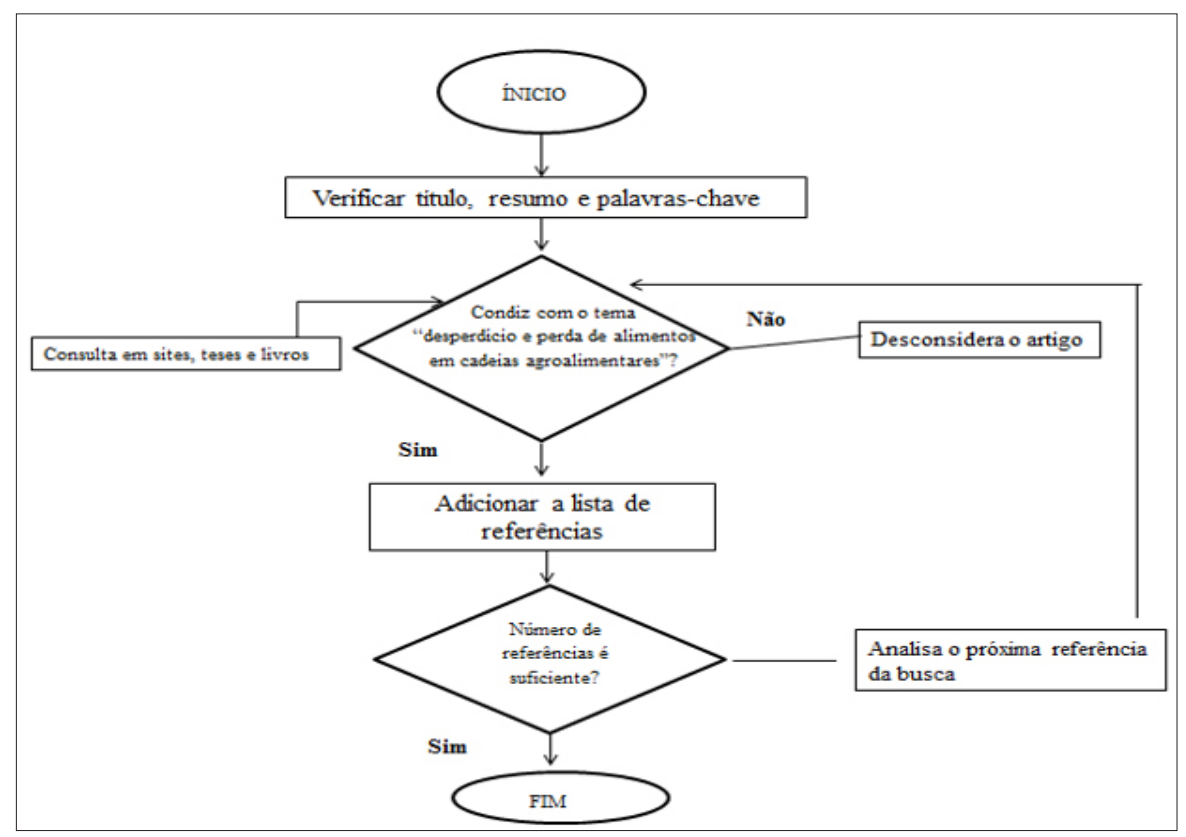

Figura 1. Framework de busca de referências.

Fonte: Autores (2016). 
Para a seleção dos artigos foi elaborado um critério de inclusão, no qual o artigo deve necessariamente abordar conceitos sobre desperdício e/ou perda de alimentos e que sejam aplicados a cadeias de suprimento agroalimentares. Os achados foram submetidos a dois filtros de pesquisa: o filtro 1 consistiu na leitura do título, resumo e palavras-chave; caso fosse ligado ao tema de pesquisa utilizava-se o filtro 2 , no qual consiste na leitura completa do artigo. Os dados extraídos tanto das bases de dados como os da pesquisa na Internet foram sumarizados e utilizados para esse artigo a fim de obter um panorama do desperdício e perda de alimentos em cadeias de suprimentos agroalimentares.

\section{REFERENCIAL TEÓRICO}

\subsection{CADEIA DE SUPRIMENTOS AGROALIMENTAR}

A cadeia de suprimentos pode ser definida como uma sequência de processos (tomada de decisão e execução) e fluxos (material, informações e dinheiro) que visam atender às exigências dos consumidores finais, ocorrendo dentro e entre as diferentes fases da cadeia, desde a produção até o consumo final. A mesma inclui não só o produtor e seus fornecedores, mas também, dependendo do fluxo logístico, transportadores, armazéns, varejistas e os próprios consumidores (VAN DER VORST et al., 2007).

Considerando a cadeia de suprimentos agroalimentar como um tipo particular de cadeia de suprimentos (ZIGGERS; TRIENEKENS, 1999), essa compreende organizações que são responsáveis pela produção e distribuição de vegetais ou produtos de origem animal. Diante disso, uma cadeia de suprimentos agroalimentar refere-se aos processos que descrevem como o alimento de uma "fazenda" acaba na mesa do consumidor, passando por diversas etapas. Os processos incluem, basicamente, a produção, transformação, distribuição, varejo, consumo e descarte. Cada passo na cadeia exige a utilização de recursos humanos e naturais, sendo que, por as relações entre os elos dependerem entre si, quando uma parte é afetada, toda a cadeia é afetada também (GRIMM et al., 2014).

Os principais desafios que essa cadeia precisa administrar especificamente relacionados ao produto são: restrições de prazo de validade, variabilidade da quali- 
dade e quantidade do fornecimento de alimentos da produção agrícola, rendimento do processo variável devido a variações biológicas, sazonalidade, fatores aleatórios relacionados com tempo e pragas e outros riscos biológicos (GRIMM et al., 2014). A cadeia de suprimentos agroalimentar merece a devida atenção, pois seu desperdício possui um grande impacto ambiental, social e econômico, além de representar uma utilização altamente ineficiente de recursos ocasionados pelo uso não sustentável de recursos naturais, matérias-primas e a crescente geração de resíduos (PAPARGYROPOULOU et al., 2014; FAO, 2016).

$\mathrm{Na}$ fase de produção, pode-se observar que os principais problemas de desperdício e perda são relacionados aos danos durante o sistema de transporte ou transporte ineficiente, problemas durante o armazenamento, perdas durante o processamento ou contaminação e embalagem inadequada (GIROTTO et al., 2015; PARFITT et al., 2010). Com relação a à fase de comercialização destacam-se problemas de conservação ou manutenção e falta de armazenamento de refrigeração (PARFITT et al., 2010). A Figura 2 procura demonstrar a quantidade perdida em casa fase da cadeia em países desenvolvidos e em desenvolvimento. Já na fase de consumo, os principais problemas envolvem o excesso de compras ou compras não apropriadas, más condições de armazenagem, excesso de preparação, porcionamento e cozimento e confusão com as informações de validade (PAPARGYROPOULOU et al., 2014). Pode-se perceber que para cada fase da cadeia, o desperdício e a perda de alimentos ocorrem de maneiras distintas e por motivos diferentes.

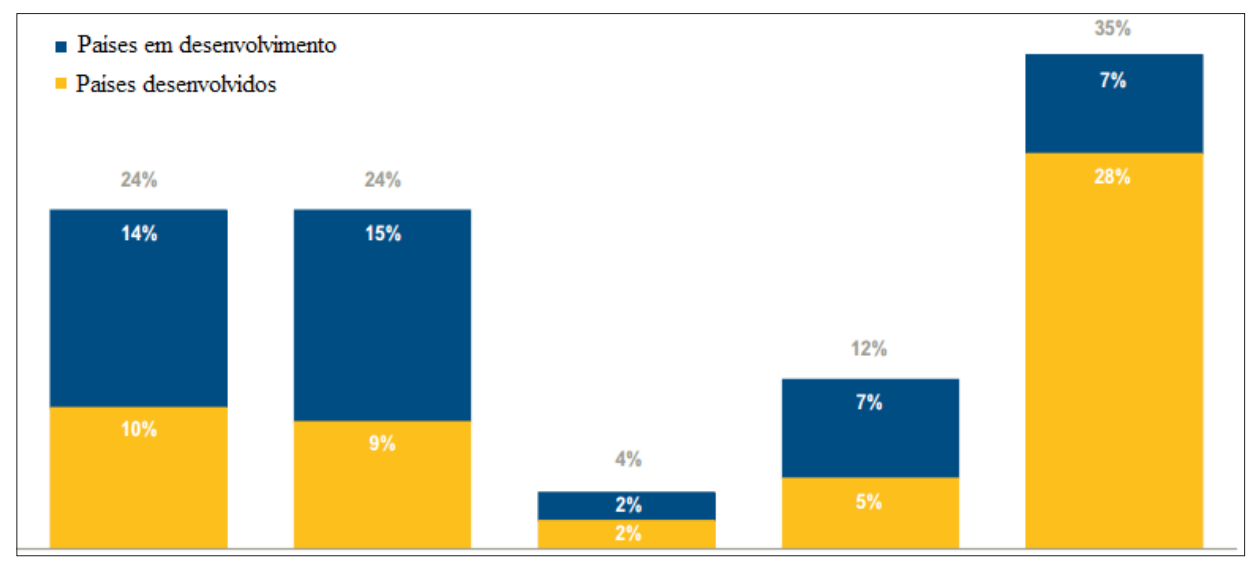

Figura 2. Desperdício e perda de alimentos ao longo da cadeia.

Fonte: Fao (2011). 
Reduzir o desperdício e a perda de alimentos nessa cadeia exige a ação de múltiplos agentes: agricultores, empresas de alimentos, distribuidores, varejistas, consumidores e governo. Por outro lado, também requer mudanças na tecnologia, comportamentos e políticas (GLOVER et al., 2014). Quando o desperdício aparece nos elos finais da cadeia, isso indica que, provavelmente, todos os processos anteriores também tiveram perdas em seus processos (BESKE et al., 2014). Quanto mais tarde um alimento se perde na cadeia, maiores são as consequências ambientais, já que os custos iniciais da produção devem ser adicionados aos custos ambientais incorridos durante o processamento, transporte, armazenamento e utilização (FAO, 2013). Nesse contexto, minimizar o desperdício de alimentos envolve uma gestão que aborde o problema de forma holística por todos os elos e agentes da cadeia (MENA et al., 2014; PAPARGYROPOULOU et al., 2014).

\subsection{DESPERDÍCIO E PERDA DE ALIMENTOS}

Existem dois termos frequentemente usados para descrever o alimento que é produzido para consumo humano, mas não é consumido (GIROTTO et al., 2015). A "perda do alimento" ocorre durante os primeiros estágios da cadeia de suprimentos, ou seja, na produção agrícola, manejo, pós-colheita e processamento de produtos na cadeia e reflete a redução não intencional de alimentos disponíveis para o consumo humano (FAO, 2013), resultado de ineficiências na cadeia e por questões climáticas, como secas e tempestades (GUSTAVSSON et al., 2011). Já o "desperdício de alimentos" se refere ao descarte intencional de itens para alimentação (FAO, 2013) ocorrendo no final da cadeia (durante a distribuição, venda e consumo final) e está ligado à ação humana, especificamente ao comportamento dos consumidores (PARFITT et al., 2010; VERGHESE et al., 2013).

Além dessa diferença, há também a relacionada ao tipo de país que se retrata, conforme visto na Figura 2, da seção 3.1. Os países em desenvolvimento estão relacionados à perda de alimentos, que ocorre principalmente nas primeiras fases da cadeia de suprimentos - agricultura, transporte e processamento - sendo que as principais razões para essas perdas estão ligadas principalmente pela ausência de infraestruturas, limitações técnicas na colheita, armazenamento e instalações de refrigeração em clima difícil, transporte ineficiente e, além disso, os aspectos 
financeiros e gerenciais, a comercialização e falta de conhecimento ou investimento (GUSTAVSSON et al., 2011). Já em países desenvolvidos, o desperdício ocorre principalmente no varejo, serviços de alimentação e nos domicílios, pois, como o alimento é mais barato nesses países, os incentivos para redução do desperdício são menores (SOHRABPOUR et al., 2012).

Nos países em desenvolvimento, muitos pequenos agricultores vivem à margem da insegurança com relação aos alimentos, sendo que uma redução das perdas de alimentos pode ter um impacto imediato e significativo sobre a sua subsistência. As cadeias de suprimentos nesses países devem ser reforçadas, incentivando os pe quenos agricultores a se organizarem, diversificarem e aumentarem sua produção e comercialização. Os investimentos em infraestrutura, transporte, indústrias de alimentos e embalagens também devem ser incentivados; juntamente com o apoio do setor público e privado que desempenham um importante papel para a realização dessas mudanças e investimentos (GIROT'TO et al., 2015).

Nos países desenvolvidos, os alimentos podem ser desperdiçados devido a padrões de qualidade, com certos itens que não se encaixam com relação à forma ou aparência obrigatória e por isso são rejeitados. No nível do consumidor, o planejamento inadequado e confusão com os termos utilizados no prazo de validade levam a grandes quantidades de desperdício, combinados com a atitude descuidada dos consumidores (GIROTTO et al., 2015). O desperdício poderia ser reduzido através da sensibilização entre as indústrias de alimentos, varejistas e consumidores (GUSTAVSSON et al., 2011).

As perdas e o desperdício de alimentos chegam a US\$ 680 bilhões nos países desenvolvidos e US\$ 310 bilhões nas nações em desenvolvimento (FAO, 2013). No caso de países em desenvolvimento, como o Brasil, as perdas correspondem a cerca de $60 \%$, principalmente na fase de pós-colheita e processamento (30\% no caso de frutas e 35\% em hortaliças) e 40\% em fases posteriores. Já em países desenvolvidos, o desperdício ocorre mais na ponta da cadeia, invertendo a projeção (GUSTAVSSON et al., 2011). Segundo a Unep (2014), o nível mais elevado de desperdício de alimentos nas sociedades ricas resulta de uma combinação entre o comportamento do consumidor e a falta de comunicação ao longo da cadeia de suprimentos.

Segundo dados da Empresa Brasileira de Pesquisa Agropecuária (Embrapa), no Brasil, contabilizam em $10 \%$ a perda de frutas e hortaliças ainda no campo, na 
fase de colheita, e indicam que a maior perda está no manuseio e transporte, cerca de $50 \%$, porém, se o alimento chega machucado, o descarte chega a ser ainda maior. Cerca de 30\% ocorre nas centrais de abastecimento, como o CEASA, e 10\% são diluídos nos supermercados e consumidores (IPEA, 2009). As grandes perdas pós-colheita, ainda na fase inicial da cadeia agroalimentar, são o principal problema, ocorrendo como resultado de limitações financeiras e estruturais nas técnicas de colheita e infraestrutura de transporte e de armazenamento, combinadas com as condições climáticas no país que favorecem a deterioração dos alimentos.

É essencial compreender tanto quanto possível a quantidade de comida que é gerada pelos diferentes elos da cadeia, as razões para o desperdício e perda, e na medida em que poderiam ser evitadas e/ou reduzidas. Esta informação pode ajudar a tomar decisões mais bem informadas, bem como fornecer soluções mais eficientes para as empresas e outras partes interessadas (UNEP, 2014).

\section{RESULTADOS E DISCUSSÕES}

Nesta seção serão apresentadas as principais cadeias agroalimentares que se destacam com relação ao desperdício e perda de alimentos, expondo seu volume, implicações, principais razões para o desperdício e/ou perda e como ocorrem ao longo da cadeia. A Figura 3 procura apresentar os principais alimentos e suas respectivas perdas e desperdício (por peso). Pode-se perceber que a cadeia que mais perde/desperdiça é a de frutas e vegetais, seguido por raízes e tubérculos e cereais. As cadeias selecionadas para esse estudo foram as mais significativas em termos de desperdício/perda e impactos ambientais que são: carnes (bovina, suína e de frango), FLV (frutas, legumes e verduras) e cereais e grãos. 


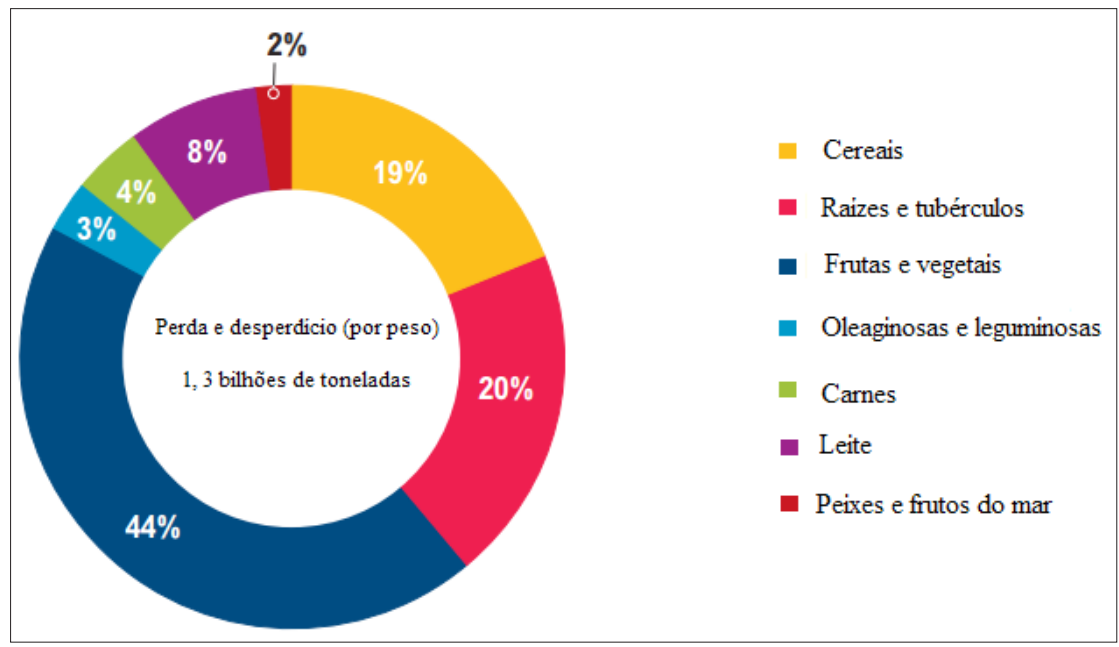

Figura 3. Perda e desperdício global de alimentos (por peso). Fonte: Fao (2011).

\subsection{CADEIA DE CARNES (BOVINA, SUÍNA E FRANGO)}

O Brasil é um grande produtor mundial de proteína animal e tem no mercado interno o principal destino de sua produção. Considerando a produção brasileira de carnes (bovina, suína e de aves) em 2010, estimada em 24,5 milhões de toneladas, temos que $75 \%$ dessa produção é consumida internamente no país. A produção de carne (bovina, suína e aves) deverá aumentar em 12,6 milhões de toneladas até 2018/2019 (MAPA, 2015).

No entanto, apesar da grande representatividade desse setor no mundo e a sua importância para a economia nacional, a utilização de recursos naturais e de infraestrutura pela cadeia é elevada, principalmente água, terra e energia (KERRY et al., 2006). Apesar do desperdício e perda da carne serem menores comparados com outros alimentos, seu desperdício resulta na perda significativa de recursos despendidos ao longo da cadeia, incluindo o uso da terra, nutrientes, fertilizantes, água e energia, além disso, possui um impacto significativo sobre a sustentabilidade global (WILLIAMS; WIKSTRÖM, 2011; VERGHESE et al., 2013).

Por tonelada de produto, os produtos de origem animal, em geral, possuem uma pegada hídrica (utilização de água no processo produtivo) maior que de pro- 
dutos vegetais. Comparando com outros produtos de origem animal, a carne bovina é a maior detentora de recursos utilizados na produção. No caso da água, para a produção de $1 \mathrm{~kg}$ de carne bovina são necessários, aproximadamente, 15 mil litros de água. Já a carne suína utiliza 6 mil litros para $1 \mathrm{~kg}$ produzido, enquanto o frango utiliza 4 mil litros para $1 \mathrm{~kg}$ produzido (MEKONNEN; HOEKSTRA, 2012).

Com relação à carne bovina, sua produção interfere negativamente no meio ambiente, pois promove o desmatamento, o efeito estufa, a poluição das águas, a redução da biodiversidade, além de ocupar muitos hectares de terra (CEDEBERG et al., 2011; STEINFELD et al., 2006; MCMICHAEL et al., 2007). Além disso, a pecuária é responsável por emitir aproximadamente 18\% dos gases de efeito estufa do mundo, poluindo mais do que o setor de transportes (STEINFELD et al., 2006). As emissões de gás carbônico $\left(\mathrm{CO}_{2}\right)$ são, em sua maioria, provenientes de devastações de florestas (utilização da terra como pasto para o gado), e as emissões de metano $\left(\mathrm{CH}_{4}\right)$ vêm majoritariamente da digestão dos ruminantes (MCMICHAEL et al., 2007; STEINFELD et al., 2006). O $\mathrm{CO}_{2}$ emitido por toda a cadeia produtiva da carne é elevado, dessa forma, sua perda e/ou desperdício possui um custo muito mais elevado em comparação com o volume perdido, por exemplo, do setor de hortifruti.

Dos 263 milhões de toneladas de carne produzidos globalmente, mais de $20 \%$ são perdidos ou desperdiçados ao longo da cadeia (FAO, 2012). Os elos da cadeia mais afetados são a distribuição, devido a ineficiências na cadeia do frio para transportar e armazenar adequadamente esse tipo de alimento, e o consumo, no qual o consumidor final detém pouca informação sobre os atributos da carne, seja por falta de conhecimento ou por falta de informações nas embalagens de produtos cárneos, no qual muitas vezes é ineficiente para armazenar esse tipo de alimento, gerando desperdícios antes mesmo de chegar à à mesa do consumidor.

Os grandes impactos ambientais da carne, combinados com os altos custos econômicos, sugerem que reduzir a sua perda e desperdício devem receber a devida atenção assim como outras commodities, pois apesar de possuir uma parcela menor de perdas e desperdício ao longo da cadeia, possui um impacto significativo sobre a sustentabilidade global (LIPINSKI et al., 2013). 


\subsection{CADEIA DE FLV (FRUTAS, LEGUMES E VERDURAS)}

O mercado de FLV (frutas, verduras e legumes) é um dos menos desenvolvidos no Brasil, sendo o crescimento limitado pela dificuldade, tanto do setor público quanto do setor privado, de estabelecer padrões mínimos sobre as características dos produtos comercializados e pela falta de políticas que incentivem o desenvolvimento de tais padrões. Além disso, percebe-se que seu consumo ainda é relativamente pequeno no Brasil (EMBRAPA, 2015).

É importante destacar que tanto o varejo como os consumidores ainda possuem a imagem de que as frutas e hortaliças, por serem produtos perecíveis, precisam estar com a aparência em perfeito estado para consumo, o que se demonstrou ser uma alegação errônea, visto que as frutas e os legumes não precisam estar com aparência perfeita para ter um sabor delicioso (UNEP, 2014). Estima-se que 20 a 40\% das frutas e legumes do Reino Unido sejam rejeitados antes mesmo de chegar às lojas, principalmente porque elas não correspondem aos rigorosos padrões estéticos dos supermercados.

De acordo com Batt (2003), no caso da distribuição de FLV, em que os preços são formados pela oferta e demanda dos produtos no mercado, há um elevado nível de incerteza para o produtor rural. Com isso, muitas vezes, os produtores plantam muito mais do que a demanda consegue suprir, excedendo a produção de alimentos, onde por falta de infraestrutura e planejamento, não irão ser comercializados ou aproveitados para outros fins, como doações, ração animal e compostagem.

Juntamente com raízes e tubérculos, as frutas e legumes têm as mais altas taxas de desperdício de quaisquer produtos, quase metade de todas as frutas e vegetais produzidos que são desperdiçados (FAO, 2012). As frutas e legumes, combinados com raízes e tubérculos, contribuem em cerca de 59\% do total de resíduos de alimentos perdidos ou desperdiçados (UNEP, 2014), podendo ser vistas as que mais se destacam na Figura 4. Dentro da cadeia de FLV, os elos da cadeia que mais se destacam são o de produção e pós-colheita, processamento e, em alguns casos, dependendo do país, a distribuição, como em países africanos e Oeste e centro da Ásia (UNEP, 2014). Na África, o processamento e a distribuição são os estágios mais frágeis, enquanto na Europa, a fase do consumo é onde corresponde o maior desper- 
dício (TIMMERMANS et al., 2014). Em específico a raízes e tubérculos, tem-se que a fase de produção e pós-colheita são as mais afetas na maioria dos países, apenas na América do Norte e Oceania é que o desperdício na fase de consumo também é visto.

\section{FRUTAS}

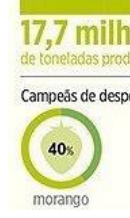

5,3 milhões

ogadas fora
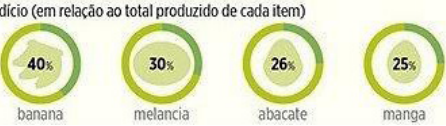

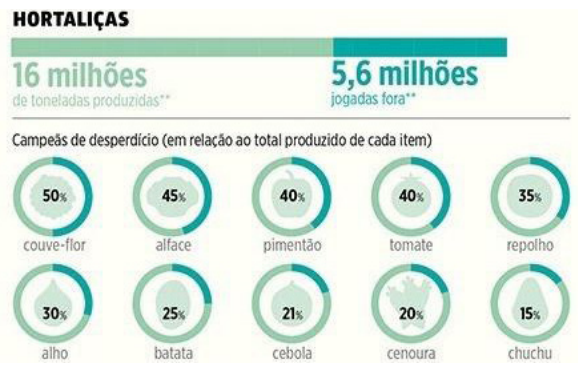

Figura 4. Desperdício de frutas e hortaliças por categoria ao ano Fonte: Fao (2011) e Unep (2014).

Muitos recipientes comuns de armazenamento usados para transportar frutas, legumes e verduras podem levar a perdas na qualidade, tais como manchas escuras ou até mesmo na perda do alimento por completo, devido a esmagamentos ou destruição durante o transporte. Embalagens comumente usadas no transporte em muitos países em desenvolvimento oferecem pouca proteção contra perdas de qualidade de compressão, punção e impacto (LIPINSKI et al., 2013). Segundo a Embrapa (2015) o transporte das frutas e hortaliças é um dos principais gargalos para a redução das perdas de alimentos no Brasil, devido principalmente a ausência de embalagens adequadas e economicamente viáveis para o produtor rural. Os supermercados também deveriam rever as regras para aquisição de produtos dentro de um determinado padrão estético. Uma possível saída seria a criação de seções com alimentos de diferentes padrões e preços dentro dos supermercados, para evitar perdas dos alimentos fora do modelo.

O elevado volume de desperdício de produtos hortícolas nos países industrializados como a Europa, Sul e Sudeste da Ásia resultam em uma grande pegada de carbono para o setor. Já o elevado nível de desperdício das frutas contribui significativamente para a utilização desnecessária de água na Ásia, Europa e América Latina (FAO, 2009). Em muitos países africanos, as frutas, legumes e tubérculos, que são menos resistentes do que os cereais, refletem perdas que podem chegar a $50 \%$ na fase de pós-colheita (FAO, 2012). 
Em comparação com a pegada hídrica da carne, as frutas necessitam, em média, de 962 litros de água para $1 \mathrm{~kg}$ de fruta e os vegetais de 354 litros para $1 \mathrm{~kg}$ (MEKONNEN; HOEKSTRA, 2011). Apesar dos impactos ambientais serem menores nessa cadeia comparada com a de carnes, o volume desperdiçado em contrapartida é extremamente elevado.

\subsection{CADEIA DE CEREAIS E GRÃOS}

Analisando o desperdício e a perda por peso, temos que as frutas e vegetais detêm a maior porcentagem das cadeias, com 44\%. Entretanto, se for analisado o desperdício e a perda por kcal, os cereais comprometem a maior porcentagem global, com 53\%, conforme a Figura 5. Esta variação resulta principalmente de diferenças no conteúdo de água, pois a maior parte do peso perdido e desperdiçado em frutas e vegetais é composta por água (FAO, 2011).

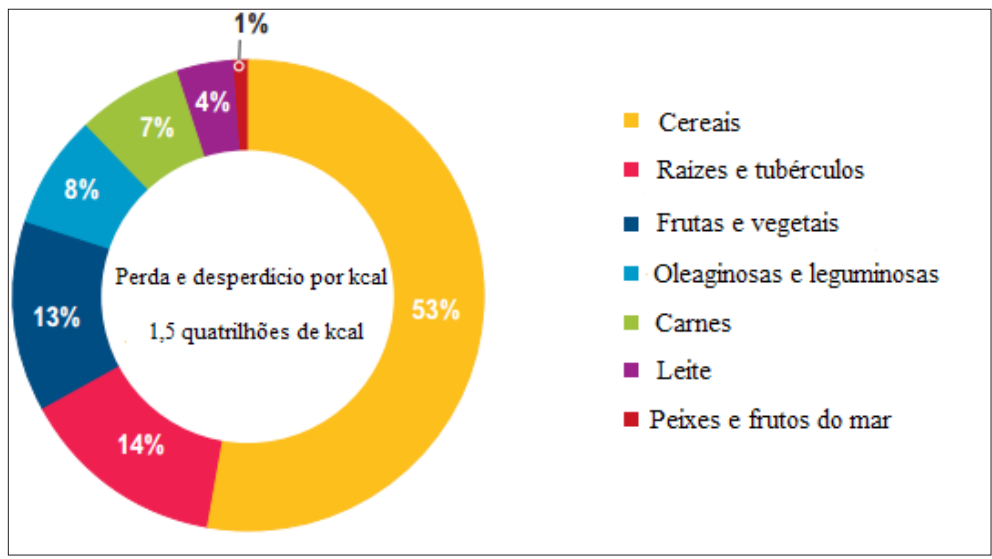

Figura 5. Perda e desperdício global de alimentos (por kcal) Fonte: Fao (2011).

Nos países da Europa, América do Norte e Oceania e Ásia industrializada, o elo do consumo é o que mais se destaca com relação ao desperdício. Apesar do consumo se destacar em regiões como a América Latina e Norte da África, Oeste e centro da Ásia, os elos da produção e pós-colheita continuam sendo os mais significativos com relação às perdas (LIPINSKI et al., 2013). Em países como a Índia, as 
perdas relacionadas aos cereais e grãos são mais baixas, cerca de $10 \%$ ou 23 milhões de toneladas de cereais. Em muitos países africanos, as perdas na pós-colheita de cereais são estimadas em $25 \%$ do total da safra colhida, ocorrendo principalmente nos primeiros elos da cadeia agroalimentar (TIMMERMANS et al., 2014). Em países industrializados, os consumidores jogam cerca de 286 milhões de toneladas de cereais (FAO, 2012). Na Europa, os cereais são perdidos em sua maioria no elo consumidor, são de 25\%, contra 1\% nesse mesmo elo na África (TIMMERMANS et al., 2014).

Em alguns países em desenvolvimento, os agricultores habitualmente deixam cereais depois de maduros, como por exemplo, o milho, em cima do campo, pois a maioria não possui instalações para secagem. No entanto, quando a época da colheita coincide com o período das chuvas, há um aumento do apodrecimento e contaminação por toxinas e fungos, sendo uma das principais causas de perdas de cereais, antes mesmo de chegar ao consumidor final (ALAKONYA et al., 2008). Para melhorar as condições de armazenamento de cereais e tubérculos, existem várias soluções, como por exemplo, tecnologias de pós-colheita desenvolvidas para proteger cereais armazenados, como sacos de grãos e silos metálicos (TEFERA et al., 2011). Entretanto, o acesso a essas soluções bem como o custo podem ser desafiadores para pequenos produtores.

A pegada hídrica referente à produção de $1 \mathrm{~kg}$ de cereais e grãos equivale a cerca de 1700 litros de água (MEKONNEN; HOEKSTRA, 2011). É importante destacar que os cereais correspondem como a principal fonte de alimentação de animais; o frango e porco possuem relativamente grandes frações de cereais e farinha de óleo em sua alimentação, o que resulta em relativamente grandes pegadas de água na alimentação desses animais (KERRY et al., 2006; MEKONNEN; HOEKSTRA, 2011).

A maior demanda de água na produção animal é a água necessária para produzir alimentos para animais. Devido ao crescimento do setor agropecuário, a demanda por alimentos desse tipo cresce, acompanhados dos cereais, raízes ricas em amido e oleaginosas (MEKONNEN; HOEKSTRA, 2011). O desperdício de carne causa uma maior alocação de cereais e grãos para servir como alimento aos animais, ao invés de aumentar o fornecimento para o consumo humano. Isso pode acarretar problemas com implicações éticas e ambientais, além de aumentar a ocupação do solo, pois, por exemplo, para produzir carne e leite desperdiçados no final da cadeia 
nos Estados Unidos e Grã-Bretanha, são necessários cerca de 8,3 milhões de hectares de terra (WILLIAMS et al., 2012).

\section{CONSIDERAÇÕES FINAIS}

O desperdício e a perda de alimentos vêm criando uma necessidade de investigação, principalmente no contexto de cadeias agroalimentares, devido suas às peculiaridades. Diante dessa realidade, ainda são necessários muitos estudos sobre o desperdício e perda de alimentos no mundo e seu impacto socioeconômico e ambiental. Por isso, o objetivo desse artigo foi fornecer um panorama do desperdício e da perda de alimentos em cadeias de suprimentos agroalimentares em um contexto mundial, apontando principalmente como é em países com desenvolvimento distintos, de que forma ocorrem na cadeia, além dos principais impactos e desafios. Entretanto, particularmente no Brasil, esses estudos são quase inexistentes e requerem um esforço conjunto de diversas organizações públicas e privadas, pois são inúmeras as formas e fontes de perda e desperdício.

Foi possível observar que das cadeias agroalimentares analisadas - carnes; frutas, legumes e verduras; e cereais - a que mais se destaca com relação ao desperdício e a perda (por peso) é a de frutas, legumes e verduras, embora seu impacto ambiental não seja tão representativo como a de carnes, especialmente a bovina, o volume perdido/desperdiçado é expressivo e merece a devida atenção para redução.

Nas cadeias analisadas, a de carnes é a que a possui a maior pegada hídrica; seguido dos cereais e grãos, frutas e vegetais. Além disso, a cadeia de carnes utiliza muitos recursos durante seus processos, como o uso da terra, nutrientes, rações baseadas em cereais, fertilizantes, água e energia. É importante destacar que, ocorrendo o desperdício e a perda da carne, há também o desperdício de cereais, considerando que é a principal fonte de alimentação de animais como o frango e porco, a utilização adequada desses cereais remete ao uso eficiente de água.

Dentre os elos das cadeias, na produção, pode-se observar que os principais problemas de perda são relacionados aos danos durante o sistema de transporte, problemas durante o armazenamento na pós-colheita, perdas durante o processamento ou contaminação e embalagem inadequada. Com relação ao consumo, os 
principais problemas envolvem o excesso de compras, más condições de armazenagem, falta de planejamento, confusão com as informações de validade, além de um preconceito - juntamente com o varejo - de alimentos com aparência não tão perfeita, mas que está adequada para o consumo.

Essa diferença entre as formas de desperdício e perda nos elos é destacada nos países em que é analisada. Em países industrializados, o desperdício ocorre principalmente no varejo, serviços de alimentação e nos domicílios, influenciados pelo comportamento do consumidor e das exigências rígidas de padrões de qualidade nos alimentos. Enquanto em países menos industrializados, as perdas ocorrem principalmente nas primeiras fases da cadeia de suprimentos, na agricultura, transporte e processamento, sendo influenciadas principalmente por mecanismos ineficientes de refrigeração, falta de infraestrutura e planejamento, processos logísticos precários ou deficientes e a falta de capacitação do produtor em boas práticas de manipulação, transporte e reaproveitamento de alimentos.

Medidas de mitigação de desperdício podem ter custos significativos, mas em compensação oferecem globalmente uma eficiência e equidade maiores. É de extrema importância que haja o estabelecimento de uma abordagem holística entre todos os participantes da cadeia de alimentos, a fim de prevenir e mitigar o desperdício e a perda de alimentos, desde o início da produção. Mesmo que o alimento não seja mais apto ao consumo humano, o mesmo pode ser reaproveitado para outras atividades econômicas por meio de técnicas de reciclagem, contribuindo para a geração de trabalho e renda; utilização para alimentação animal e compostagem. Além disso, capacitar produtores, atacadistas, varejistas, técnicos e especialistas na cadeia produtiva para a aplicação de técnicas e tecnologias que minimizem perdas e ampliem melhorias no setor agroalimentar, bem como mais recursos para a pesquisa, desenvolvimento de embalagens adequadas, melhoria da cadeia de frio na infraestrutura de logística e transporte de produtos alimentícios, dentre outros mecanismos para promover a produção e o desenvolvimento sustentável de alimentos.

Em se tratando do Brasil, uma estratégia inicial e imediata para a redução do desperdício/perda seria a elaboração de um diagnóstico mais recente sobre a questão de perdas e desperdício de alimentos no país, sendo realizado por instituições governamentais e de pesquisa para a proposição de novas políticas públicas e priva- 
das. Outra solução imediata seria o aproveitamento integral dos alimentos, inclusive daqueles fora do padrão de consumo, com a integração das práticas de pós-colheita, de processamento de alimentos e de aproveitamento de produtos, para geração de renda e agregação de valor à produção, além da utilização de restos de comida para compostagem de hortas.

Esse artigo possui algumas limitações, como a falta de análises em cadeias agroalimentares como a de ovos, leite e derivados e peixes e frutos do mar, bem como o aprofundamento dos dados e análises nas cadeias aqui destacadas. Nesse âmbito, destaca-se a necessidade de estudos mais aprofundados, principalmente no Brasil, para avaliar e compreender o desperdício e a perda de alimentos nas cadeias. O correto diagnóstico é o primeiro passo para poder entender os problemas encontrados por cada elo da cadeia bem como em criar estratégias e mecanismos mais adequados para a realidade brasileira, visto que, as iniciativas em países industrializados, além de estarem em um estágio mais avançado, são criadas para responder suas respectivas dificuldades nesse contexto de desperdício.

\section{REFERÊNCIAS}

ALAKONYA, A. E.; MONDA, E. O.; AJANGA, S. Effect of delayed harvesting on maize ear rot in Western Kenya. American-Eurasian Journal of Agriculture and Environment, v. 4, n. 3, p. 372-380, 2008.

BATALHA, M. O.; SILVA, A. L. Gerenciamento de sistemas agroindustriais: definições e correntes metodológicas (capítulo 1). In: BATALHA, M. O. (coord.). Gestão agroindustrial. 4. ed. São Paulo: Atlas, 2007.

BATT, P. F. Building trust between growers and market agentes. Supply Chain Ma nagement: an international journal, v. 8, n. 1, p. 65-78, 2003.

BERTO, R.; NAKANO, D. Metodologia da pesquisa e a Engenharia de Produção In: XVIII Encontro Nacional de Engenharia de Produção, 1998. Niterói. Anais... Rio de Janeiro: ABEPRO, 1, 1998.

BESKE, P.; SEURING, S. Putting sustainability into supply chain management. Supply Chain Management: an international journal, v. 19, n. 3, p. 322-331, 2014. 
CEDERBERG, C.; PERSSON, U. M.; NEOVIUS, K.; MOLANDER, S.; CLIFT, R. Including carbon emissions from deforestation in the carbon footprint of Brazilian beef. Environmental Science \& Technology, v. 45, n. 5, p. 1773-1779, 2011.

DARKOW, I. L.; FOERSTER, B.; VON DER GRACHT, H. A. Sustainability in food service supply chains: future expectations from European industry experts toward the environmental perspective. Supply Chain Management: An International Journal, v. 20, n. 2, p. 163-178, 2015.

ELLRAM, L. M. The use of the case study method in logistics research. Journal of business logistics, v. 17, n. 2, 93, 1996.

EMBRAPA. Empresa Brasileira de Pesquisa Agropecuária. Pesquisa identifica fatores de desperdício de alimentos em famílias de baixa renda. 2015. Disponível em: https://www.embrapa.br/web/portal/busca-de-noticias/-/noticia/3381192/pesquisa-identifica-fatores-de-desperdicio-de-alimentos-em-familias-de-baixa-renda Acesso em: jul. 2016.

FAO. Food and Agriculture Organization of the United Nations. Global food losses and food waste-extent, causes and prevention. 2011. Rome: UN FAO.

FAO. Food and Agriculture Organization of the United Nations. Technical Platform on the Measurement and Reduction of Food Loss and Waste. 2012. Disponível em: http://www.fao.org/platform-food-loss-waste/en/ Acesso em: jul. 2016.

FAO. Food and Agriculture Organization of the United Nations. The State of Food and Agriculture. 2013. Disponível em: http://www.fao.org/docrep/018/i3300e/ i3300e.pdf Acesso em: jan. 2015.

FAO. Food and Agriculture Organization of the United Nations. Increasing the resilience of agricultural live lihoods. 2016. Disponível em: http://www.fao.org/3/a-i5615e.pdf Acesso em: jun. 2016.

GARRONE, P.; MELACINI, M.; PEREGO, A. Opening the black box of food waste reduction. Food Policy, v. 46, p. 129-139, 2014.

GIORDANO, R. B.; ALMEIDA BIOLCHINI, J. C. Busca e recuperação da informação científica na web: comportamento informacional de profissionais da informação. InCID: Revista de Ciência da Informação e Documentação, v. 3, n. 1, p. 125-145, 2012. 
GLOVER, J. L.; CHAMPION, D.; DANIELS, K. J.; DAINTY, A. J. D. An Institutional Theory perspective on sustainable practices across the dairy supply chain. International Journal of Production Economics, v. 152, p. 102-111, 2014.

GÖBEL, C.; LANGEN, N.; BLUMENTHAL, A.; TEITSCHEID, P.; RITTER, G. Cutting food waste through cooperation along the food supply chain. Sustainability, v. 7 , n. 2, p. 1429-1445, 2015.

GRIMM, J. H.; HOFSTETTER, J. S.; SARKIS, J. Critical factors for sub-supplier management: A sustainable food supply chains perspective. International Journal of Production Economics, v. 152, p. 159-173, 2014.

GUSTAVSSON, J.; CEDERBERG, C., SONESSON, U.; OTTERDIJK van, R.; MEYBECK, A. Global Food Losses and Food Waste. In: Food and Agriculture Organization of The United Nations, 2011. Disponivel em: http://www.fao.org/docrep/014/mb060e/ mb060e00.pdf. Acesso em: nov. 2013.

IPEA. Instituto de Pesquisa Econômica Aplicada. Desperdício - Custo para todos Alimentos apodrecem enquanto milhões de pessoas passam fome. 2009. Disponível em: http://www.ipea.gov.br/desafios/index.php?option $=$ com_content\&view $=$ article\&id=1256: catid = 28\&Itemid =23 Acesso em: jul. 2016.

JOHNSON, P.; BUEHRING, A.; CASSELL, C.; SYMON, G. Defining qualitative management research: an empirical investigation. Qualitative research in organizations and management: an international journal, v. 2, n. 1, p. 23-42, 2007.

KERRY, J. P.; O'GRADY, M. N.; HOGAN, S. A. Past, current and potential utilisation of active and intelligent packaging systems for meat and muscle-based products: A review. Meat Science, v. 74, n. 1, p. 113-130, 2006.

LIPINSKI, B.; HANSON, C.; LOMAX, J.; KITINOJA, L.; WAITE, R.; SEARCHINGER, T. Reducing food loss and waste. World Resources Institute Working Paper, June, 2013.

MAPA. Ministério da Agricultura, Pecuária e Abastecimento. Animal: Bovinos e bubalino. 2015. Disponível em: http://www.agricultura.gov.br/animal/especies/bovinos-e-bubalinos Acesso em: fev. 2015. 
MCMICHAEL, A. J.; POWLES, J. W.; BUTLER, C. D.; UAUY, R. Food, livestock production, energy, climate change, and health. The Lancet, v. 370, n. 9594, p. 1253-1263, 2007.

MEKONNEN, M. M.; HOEKSTRA, A. Y. The green, blue and grey water footprint of crops and derived crop products. Hydrology and Earth System Sciences, v. 15, n. 5, p. 1577-1600, 2011.

MEKONNEN, M. M.; HOEKSTRA, A. Y. A global assessment of the water footprint of farm animal products. Ecosystems, v. 15, n. 3, p. 401-415, 2012.

MENA, C.; TERRY, L. A.; WILLIAMS, A.; ELLRAM, L. Causes of waste across multi-tier supply networks: Cases in the UK food sector. International Journal of Production Economics, v. 152, p. 148-155, 2014.

PAPARGYROPOULOU, E.; LOZANO, R.; STEINBERGER, J. K.; WRIGHT, N.; UJANG, Z. $B$. The food waste hierarchy as a framework for the management of food surplus and food waste. Journal of Cleaner Production, v. 76, p. 106-115, 2014.

PARFITT, J.; BARTHEL, M.; MACNAUGHTON, S. Food waste within food supply chains: quantification and potential for change to 2050. Philosophical Transactions of the Royal Society of London B: Biological Sciences, v. 365, n. 1554, p. 3065-3081, 2010.

PORTAL BRASIL. Embalagens de plástico verde reduzem desperdício e são mais seguras. 2014. Disponível em: http://www.brasil.gov.br/ciencia-e-tecnologia/2014/08/embalagens-de-plastico-verde-reduzem-desperdicio-e-sao-mais-seguras Acesso em: jan. 2015.

SOHRABPOUR, V.; HELLSTRÖM, D.; JAHRE, M. Packaging in developing countries: identifying supply chain needs. Journal of Humanitarian Logistics and Supply Chain Management, v. 2, n. 2, p. 183-205, 2012.

STEINFELD, H.; GERBER, P.; WASSENAAR, T.; CASTEL, V.; ROSALES, M.; HAAN, C.; Livestock's long shadow: environmental issues and options. Food and Agriculture Organization of the United Nations: Roma, 2006.

TEFERA, T.; KANAMPIU, F.; DE GROOTE, H.; HELLIN, J.; MUGO, S.; KIMENJU, S.; BEYENE, Y.; BODDUPALLI, P. M.; SHIFERAW, B.; BANZIGER, M. The metal silo: an 
effective grain storage technology for reducing postharvest insect and pathogen losses in maize while improving smallholder farmers' food security in developing countries. Crop Protection, v. 30, n. 3, p. 240-245, 2011.

THYBERG, K.; TONJES, D. J. Drivers of food waste and their implications for sustainable policy development. Resources, Conservation and Recycling, v. 106, p. 110-123, 2016.

TIMMERMANS, A. J. M.; AMBUKO, J.; BELIK, W.; HUANG, J. Food losses and waste in the context of sustainable food systems. CFS Committee on World Food Security HLPE, n. 8, 2014.

UN. The United Nations. World Population Prospects The 2012 Revision. 2013. Disponível em: http://esa.un.org/wpp/Documentation/pdf/WPP2012_Volume-I_ Comprehensive-Tables.pdf Acesso em: 23 jan. 2015.

UNEP. United Nations Environment Programme. Prevention and reduction of food and drink waste in businesses and households - Guidance for governments, local authorities, businesses and other organisations. 2014. Disponível em: http://www. thinkeatsave.org/downloads/UNEP-FW-Guidance-content-VERSION-WEB.pdf Acesso em: jul. 2016.

VAN DER VORST, J. G.; DA SILVA, C. A.; TRIENEKENS, J. H. Agro-industrial supply chain management: concepts and applications. 2007. FAO.

VERGHESE, K.; LEWIS, H.; LOCKREY, S.; WILLIAMS, H. Final report: The role of packaging in minimising food waste in the supply chain of the future. RMIT University - Centre for Design, v. 3, n. 3, p. 1-50, 2013.

VILELA, N. J.; HENZ, G. P. Situação atual da participação das hortaliças no agronegócio brasileiro e perspectivas futuras. Cadernos de Ciência \& Tecnologia, v. 17, n. 1, p. 71-89, 2000.

ZIGGERS, G. W.; TRIENEKENS, J. Quality assurance in food and agribusiness supply chains: Developing successful partnerships. International Journal of Production Economics, v. 60, p. 271-279, 1999. 
WILLIAMS, H.; WIKSTRÖM, F. Environmental impact of packaging and food losses in a life cycle perspective: a comparative analysis of five food items. Journal of Cleaner Production, v. 19, n. 1, p. 43-48, 2011.

WILLIAMS, H.; WIKSTRÖM, F.; OTTERBRING, T.; LÖFGREN, M.; GUSTAFSSON, A. Reasons for household food waste with special attention to packaging. Journal of Cleaner Production, v. 24, p. 141-148, 2012.

Recebido em: 23/08/2016 Aceito em: 01/10/2017 